\title{
Transformatör üreten bir firmada risk analizinde bulanık HTEA kullanımı ve uygulama yazılımı geliştirme
}

\author{
Mert TURAN ${ }^{1}$, Demet GÖNEN OCAKTAN ${ }^{2, *}$ \\ ${ }^{1}$ Balıkesir Elektromekanik Sanayi Tesisleri A.S., Balıkesir \\ ${ }^{2}$ Balıkesir Üniversitesi, Mühendislik Fakültesi, Endüstri Mühendisliği Bölümü, Çağış Kampüsü, Balıkesir
}

Geliș Tarihi (Recived Date): 15.12.2018

Kabul Tarihi (Accepted Date): 01.02.2019

\begin{abstract}
Özet
Işsletmelerin güçlü bir güvenilirliği yönetmek için yapısal bir yöntem kullanmalar ve risk analizi yapmaları zorunludur. Risk analizi, işletmeler için mevcut veya olası tehlikelerin belirlenmesi, bu tehlikelerden kaynaklanan/kaynaklanabilecek risklerin analiz edilerek derecelendirilmesi ve oluşmalarının önlenmesi amacıla yapılması gerekli çalışmaları ifade eder. Risk analizinin birçok yöntemi vardır. Hata Türü ve Etkileri Analizi (HTEA)'da sistemdeki olası hataların, ortaya çıkmadan tespit edilmesini ve öncelikli olandan başlayıp iyileştirilmesini sağlayan bir metottur. Bu yöntem, belirli bir sistemin incelenerek, güvenilirliğinin artırllabilmesi ve hatalardan arındırılabilmesi için ne şekilde geliştirilebileceğinin belirlenmesi için kullanılır. Bu çalışmada transformatör üreten bir firmanın süreçlerinde ortaya çıkabilecek hataların tespit edilerek önlem alınması ve firma güvenilirliğinin artırılması hedeflenmiştir. Işletmenin güç transformatörü ürün grubu ele alınmış ve riskleri önceliklendirmek için bulanık mantıkla hata türü ve etkileri analizi (Bulanık HTEA) kullanılmıştır. Klasik HTEA'da gerçekleştirilen Tasarım ve Proses HTEA çalışmaları ile risk öncelik değeri yüksek ve öncelikle iyileştirilmesi gereken hatalar belirlenmiştir. Risk öncelik değerinin hesaplanmasında sözel ifadelerin kullanılması ve değerlendirmenin kişiye bağlı olması gibi eksikler dikkate alındığında HTEA yönteminin Bulanık Mantık ile kullanılmasının yararlı olacă̆ sonucuna varılmıştır. Yapılan Bulanık HTEA çalışmaları sonucunda elde edilen hatalara ait risk öncelikleri değerlendirildiğinde kullanılan yöntemin gerçeğe daha yakın sonuç verdiği görülmüsş ve işletmede yapılan çalışmanın etkinliğini ve sürekliliğini sağlamak için bir HTEA takip sistemi gelişstirilmiştir.
\end{abstract}

Anahtar kelimeler: Risk analizi, hata türü ve etkileri analizi (HTEA), bulanık HTEA, bulanı HTEA risk takip programı.

Mert TURAN, mertturan1993@gmail.com, https://orcid.org/0000-0002-1451-3910

* Demet GÖNEN OCAKTAN, dgonen@balikesir.edu.tr, https://orcid.org/0000-0003-1997-6719 


\title{
Fuzzy FMEA usage and application software development in risk analysis in a transformer generating firm
}

\begin{abstract}
It is necessary for the companies to use a structured method to manage a powerful reliability, and to made risk analysis is essential. Risk analysis refers to the studies required to determine the existing or potential hazards for companies, to analyze and rate the risks arising from these hazards and to prevent them from occurring. There are several methods of risk analysis. Failure Mode and Effect Analysis (FMEA) is a method that is to ascertain the failures and dangers in the system without causing any accidents and to make them better by starting from the top priority of them. This method is used to define how the system can be developed to increase reliability and make free from failures. In this study, it is aimed to determine the mistakes that may occur in the processes of a company that produces transformers and to take precautions and increase the reliability of the company. The power transformer product group of the company has been focused on, and fuzzy logic based failure mode and effect analysis (Fuzzy FMEA) has been used to prioritize risks. High risk priority values and failures that need to be improved have been identified by design and process FMEA studies in the classical FMEA. Considering the deficiencies such as use of linguistic expressions in the calculation of risk priority value and the depens on the person of the evaluation, it was concluded that using Fuzzy Logic based FMEA method would be beneficial. When the risk priorities of the failures obtained as a result of the Fuzzy FMEA studies are evaluated, it is seen that the method used is closer to the truth, and a FMEA monitoring system has been developed to ensure the effectiveness and continuity of the work carried out in the company.
\end{abstract}

Keywords: Risk analysis, failure mode and effects analysis (FMEA), fuzzy FMEA, fuzzy FMEA risk tracking program.

\section{Giriş}

Günümüz rekabet koşullarında firmaların pazar paylarını koruyabilmeleri için maliyetlerini düşürmeleri gerekmektedir. İşletmeler için süreçlerinde ortaya çıkan problemler; katma değer yaratmayan, maliyetlerini arttıran ve müşteri memnuniyetsizliğine yol açan önlenmesi gereken durumlardır. Firmalar rekabet güçlerini korumak ve pazardaki devamlılıklarını sağlamak için süreç içerisindeki güvenirliklerini artırmak zorundadırlar. Firmaların, güvenilirliği artırarak riskleri azaltmak için kullandıkları risk analizi yöntemlerinden biri; sistem, servis, tasarım ve üretim süreçlerine ait risklerin oluşmadan önce tespit edilmesini, önem derecelerinin belirlenmesini, değerlendirilmesini ve önlenmesi için uygun önlemlerin alınmasını sağlayan Hata Türleri ve Etkileri Analizi (HTEA) yöntemidir. Bu yöntemde risklerin önem dereceleri; riskler için belirlenen olasılık, şiddet ve tespit edilebilirlik değerlerinin çarpımından oluşan Risk Öncelik Katsayısına (RÖS) göre belirlenmektedir.

HTEA, ilk olarak 1960'larda havacılık endüstrisinde tasarım metodolojisi olarak geliştirilmiştir [1]. HTEA, 1975'te bilgisayar üretiminde ve Japon NEC firmasında 
uygulanmıştır. Yöntemin kullanımı, 1977'de otomobil endüstrisinde faaliyet gösteren Ford, 1985'de Fiat firmalarında olmak üzere otomotiv endüstrisinde yayılmış ve Chrysler ve General Motors'ta da uygulamaları gerçekleştirilmiştir [2]. Risk analizi literatürü incelendiğinde HTEA yönteminin endüstride yaygın şekilde kullanıldığı görülmektedir. Erginel [2] mekanik termostatın parçalarının tasarımında, Aran ve Çevik [3] motor piston üretim sürecinde, Dıră̆ [4] dikiş sürecinde yaşanan başarısızlıklar için, Demirer ve Kahraman [5] bir otomobil fabrikasına iş sağlığı ve güvenliği alanında, Çeber [6] deterjan üretimi yapan bir fabrikanın üretim sürecinde, Şimşir ve ark. [7] haddeleme ile üretim yapan bir demir-çelik tesisinde kalite problemlerini azaltmak için HTEA yöntemini kullanmışlardır.

HTEA' da şiddet, oluşma ve tespit edilebilirlik faktörleri uzmanların bilgisine dayalı olarak belirlenebilmektedir ve genellikle risk faktörlerinin kesin bir biçimde değerlendirilmesi güçtür. Bunun yanı sıra yöntemde risk faktörleri arasındaki göreceli önem dereceleri de dikkate alınmaz. Bu nedenlerle HTEA ile elde edilen sonuçlar gerçek risk önceliklerini göstermeyebilir. Uzmanların risk faktörlerini değerlendirmede kesin değerler yerine; az, çok, önemli, yüksek gibi dildeki sözel terimleri kullanmaları çok daha kolay ve gerçekçidir. HTEA yönteminde uzmanların risk faktörlerini belirlemede kesin değerler belirlemeleri gerekmesinden kaynaklanan bu yetersizlikler, bulanık mantık yaklaşımıyla azaltılabilir. Bulanık mantık, kesin olarak bilinemeyen bilgilere dayanarak tutarlı ve doğru kararlar vermeyi sağlayan bir yaklaşımdır. Bu yaklaşım, makinelere insanların özel verilerini işleyebilme ve onların deneyimlerinden ve önsezilerinden yararlanarak çalışma imkânı vermektedir. Bu yapıda sözel ifadeler kullanılır. Sözel ifadelerin bilgisayara aktarılması matematiksel bir temele dayanmaktadır. Bulanık mantık işlemleri, problemin tanımlanması ve analiz edilmesi, kümelerin ve mantıksal ilişkilerin oluşturulması, mevcut bilgilerin bulanık kümeler şeklinde ifade edilmesi ve modelin yorumlanması aşamalarından oluşmaktadır [8,9].

Bayar [10], İstanbul Boğazı bölgesinde bugüne kadar yaşanmış kazaların oluşma nedenleri üzerinde Bulanık AHP (Bulanık Analitik Hiyerarşi Prosesi) ve HTEA yöntemleri ile Boğaz trafiği risklerini analiz etmiştir. Dinmohammadi ve Shafiee [11], özellikle hata verisinin belirsiz ve mevcut olmadığı durumlarda klasik HTEA'nın daha uygulanabilir olması için bir Bulanık HTEA yaklaşımı geliştirmiş ve bir offshore rüzgar türbini sisteminde yöntemi uygulamıştır. Yörükoğlu [12], yenilenebilir enerji kaynaklarından oluşabilecek risklerin tespiti, giderilmesi veya iyileştirilmesi amacıyla, HTEA ve Bulanık HTEA teknikleri kullanılarak risk analizleri gerçekleştirmiştir. Özfırat [13], en riskli sektörlerden biri olarak kabul edilen madencilik sektörüne HTEA ve bulanık mantık yöntemlerini kullanarak bir risk analizi gerçekleştirmiştir. Çakmak [14], Bulanık HTEA yöntemiyle demir çelik haddeleme süreçlerinde oluşabilecek risklerin önlenmesini amaçlamıştır. Roghanian ve Mojibian [15], Bulanık HTEA yöntemini risk yönetimindeki hataları azaltmak için proje risk değerlendirmede kullanmıştır. Hayati ve Abroshan [16], bir inşaat projesindeki risklerin tanımlanması, değerlendirilmesine HTEA yöntemini ve tutarlı ve mantıksal bir analiz yapmak için tamamlayıcı bir araç olarak bulanık mantık kullanmışlardır. Yazdi ve ark. [17] uçak iniş sisteminde oluşabilecek hataları değerlendirmede, Tekez [18] örme sürecinde meydana gelen hataların belirlenmesinde ve iyileştirilmesinde HTEA ve Bulanık HTEA yönteminden yararlanmışlardır.

Proje tipi üretimlerde sipariş olarak alınan her bir ürünün tüm süreçleri en baştan tekrar gerçekleştirilir. Bu nedenle bu tip üretimlerde her bir siparişin karşılanmasında tasarım 
ve üretim süreçlerinde olası riskler ile yeniden karşılaşılmaktadır. $\mathrm{Bu}$ makalede elektromekanik endüstrisinde proje tipi üretim gerçekleştiren bir işletmede tasarım ve üretim süreçlerindeki riskler klasik HTEA ve klasik HTEA'nın yetersiz kaldığı RÖS hesaplama noktasında bulanık HTEA yöntemleri ile analiz edilmiștir. Makalenin ikinci bölümünde klasik HTEA ve bulanık HTEA yöntemleri detaylandırılmıştır. Üçüncü bölümde uygulama çalışması verilmiş ve sonuç bölümü ile makale tamamlanmıştır.

\section{Metot}

$\mathrm{Bu}$ makalede elektromekanik endüstrisinde proje tipi üretim yapan bir işletmenin tasarım ve üretim süreçlerindeki risklerin analizinde klasik HTEA ve bulanık HTEA yöntemleri kullanılmıştır.

\subsection{Hata türleri ve etkileri analizi}

HTEA, potansiyel hataların ortaya çıkmasını önleyecek sistemlerin kurulmasının yanında süreç güvenilirliğini de artırmak için birçok alanda yaygın olarak kullanılan bir tekniktir. Yöntem, sistemdeki riskleri analiz etmekte, olası risklerin ortadan kaldırılmasını sağlamaktadır [19]. HTEA'da risk önceliği yaklaşımı risk değerlendirmesi için klasik bir yöntemdir [20]. HTEA; "Hataya ne sebep olmuş olabilir?", "Hatanın kök nedenleri neler olabilir?", "Hatanın sonucunda yaratacağı etkiler neler olabilir?"gibi sorulara cevap arayan ve aldığı cevapları analiz edip belgelendiren bir yöntemdir [21]. Potansiyel başarısızlıkları değerlendirmede ve oluşmalarını önlemede yararlı ve güçlü bir araç olduğu kanıtlanmıştır. Analizdeki temel amaç, hataların müşteriye ulaşmadan önce belirlenmesi ve ortadan kaldırılmasıdır. HTEA, risk analizi yapmak isteyen firmalar tarafından en fazla kullanılan risk değerlendirme araçlarından biridir [22].

HTEA çalışmalarına başlarken ekip oluşturulmalıdır. HTEA çalışmalarının etkinliği, ekibin etkili çalışması ile sağlanabilmektedir. Üzerinde çalışılacak ürünün belirlenmesinin ardından, ürünün işlevini yerine getiremediği durumlar yani olası/mevcut hatalar listelenir. Bu hataların oluşmaları durumunda yaratacağı etkiler belirlenip, bu etkiler önem derecelendirme tablolarına göre puanlandırılır. Hataları oluşturan tüm olası nedenler listelendikten sonra hataların bu nedenlerin sonucunda ne kadar sıklıkla ortaya çıkabileceği belirlenir. Hatayı ortaya çıkarmak veya önlemek için uygulanan mevcut kontroller listelenir. $\mathrm{Bu}$ kontrol yöntemleri ile mevcut veya oluşabilecek hataların belirlenmesi değerlendirilir. Belirlenen şiddet, oluşma olasılığı ve tespit edilebilirlik değerlerinin çarpılması ile hataların risk öncelik değerleri (RÖS) bulunur. Üç kriterin değerlendirmesi 1-10 skalasında gerçekleştirilmektedir. Hataların risk değerini belirleyen RÖS değerleri dikkate alınarak, öncelikle iyileștirilmesi gereken hatalar belirlenir ve düzeltici önerilerde bulunulur. Ağırlıklı olarak RÖS değeri 100 puanın üstünde kalan risklere aksiyon belirlenmektedir [16,23]. Amaç, şiddet, oluşma olasılığ ve tespit edilebilirlik değerlerinden birini veya tamamını azaltmaktır. Önerilen iyileştirmeler, sorumlu bölüm ve tamamlanma tarihi belirtilerek yazılmalıdır. İyileştirici önlemler gerçekleştirildikten sonra risk öncelik sayısı tekrar hesaplanmalıdır. $\mathrm{Bu}$ değer başlangıç durumuna göre daha düşük olarak bulunduğunda, kalitenin geliştirilmiş ve hata oranının azaltılmış olduğu düşünülmektedir [24]. 


\subsection{Bulanık HTEA}

HTEA çalışmalarında amaç, sistemden, tasarımdan, süreçten veya servisten kaynaklanabilecek olası hataların belirlenmesi, yüksek risk öncelik sayısına sahip hataların önlenmesi ve kaynakların daha verimli bir şekilde kullanılmasını sağlamaktır [25]. Artan uygulamaları ile birlikte bazı eksiklikleri ortaya çıkmıştır. HTEA yönteminde şiddet, oluşma olasılığı ve tespit edilebilirlik değerlerinin eşit önem derecesine sahip olduğu kabul edilmektedir. Ancak işletmelerde değerlendirme yapılırken bu kabul hatalı olabilmektedir. Şiddet, oluşma olasılığı ve tespit edilebilirlik değerleri düşük olan bir hata ile önem değeri yüksek olan başka bir hatanın RÖS değeri aynı çıkabilmekte ve bu iki hata eşit riskli olarak değerlendirilmektedir. RÖS değeri düşük ancak oluşması durumunda yaratacağı etkinin büyük olacağı hatalara öncelik verilemeyecektir. Bir diğer eksiklik olarak, HTEA yönteminde hataların şiddet, olasılık ve tespit edilebilirlik derecelerinin tanımlarının sözel olması ve riskler derecelendirilirken kişiden kişiye değişebileceğidir. $\mathrm{Bu}$ durum bazı önemli risklerin sınır değerinin altında kalmasına, bazı risklerin de gereğinden fazla önemli çıkmasına neden olabilir. HTEA'da ortaya çıkan bu eksiklikleri gidermek ve iyileştirmek için birçok değişiklik yapılmış veya farklı yöntemler ile birleştirilerek uygulanmıştır. Bu yöntemlerin başında bulanık mantık gelmektedir. Bu çalışmada da bu amaçla Bulanık HTEA yöntemi kullanılmıştır [8,16,26].

Bulanık mantık, karar vermede belirsizlikle başa çıkmak için Lotfi A. Zadeh tarafından geliştirilmiş analitik bir yöntemdir. Analiz edilen sistemlerin matematiksel olarak modellenmesi mümkün değilse, sistemdeki kişilerin net olmayan bilgiler 1 şı ğında anlamlı kararlar vermeleri için kullanılır [8]. Bilinmeyen durumların tanımlanması ve belirsizlikler karşısında çalışılabilmesi için oluşturulmuş bir yapıdır. Bulanık mantık ile sözle açıklanabilen durumlar, sayısal değerlere dönüştürülür [27].

Bir bulanık mantık sistemi; bulanıklaştırıcı, üyelik fonksiyonları, bulanık kural tabanı, çıkarım ve bir durulaştırıcıdan oluşur. İlk olarak dilsel değişkenler ve terimler tanımlanır. Üyelik fonksiyonlanı ve kural tabanı oluşturulur. Üyelik işlevleri kullanılarak net giriş verileri bulanık değerlere dönüştürülür (bulanıklaştırma). Bulanıklaştırma işleminde gerçek girişler, birer üyelik fonksiyonuna tabi tutularak ait oldukları bulanık kümedeki üyelik derecelerine sahip olurlar [28].

Sistemin girişi ile çıkışı arasındaki ilişkiyi tanımlayan ve karar verme işleminde kullanılan kural tabanındaki kurallar değerlendirilir ve her kuralın sonuçları birleştirilir (çıkarım). Son olarak elde edilen bulanık değerler, durulaştırıcı tarafından gerçek veya kesin değerlere dönüştürülür (durulama) [8,9].

Durulama işleminde, her kural için üyelik aralık değerleri bulunarak çıkış üyelik değerleri tespit edilir. Bulanık mantık denetleyici biriminde durulama işlemi için en çok kullanılan yöntemlerden birisi ağırlık merkezi yöntemidir. Ağırlık merkezi yöntemi ile birlikte en büyük üyelik derecesi, en büyüklerin ortalaması yöntemi, iki bölge yöntemi, toplamların merkezi yöntemi, yükseklik yöntemi, düzenlenmiş yükseklik yöntemi, kümelerin merkezi yöntemi gibi birçok durulaştırma yöntemi bulunmaktadır. Şekil 1'de a) maksimum değerlerin en düşüğü, b) ağırlık merkezi, c) maksimum değerlerin ortalaması ve d) maksimum değerlerin en büyüğü yöntemlerinden elde edilen durulaştırma değerleri görülmektedir [12, 29]. 


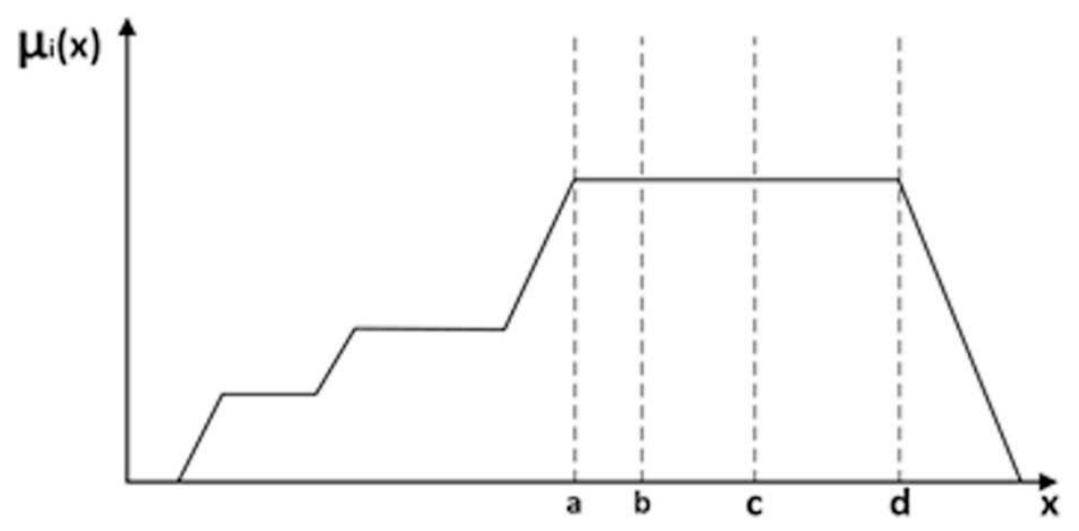

Şekil 1. Durulaştırma yöntemleri [12].

Bu çalışma kapsamında kullanılan ağırlık merkezi yönteminin durulanmış çıkış değeri Eşitlik 1'de verilen formül ile hesaplanır [29].

$$
Z=\frac{\int_{a}^{b} \mu_{C}(Z) z d z}{\int_{a}^{b} \mu_{C}(Z) d z}
$$

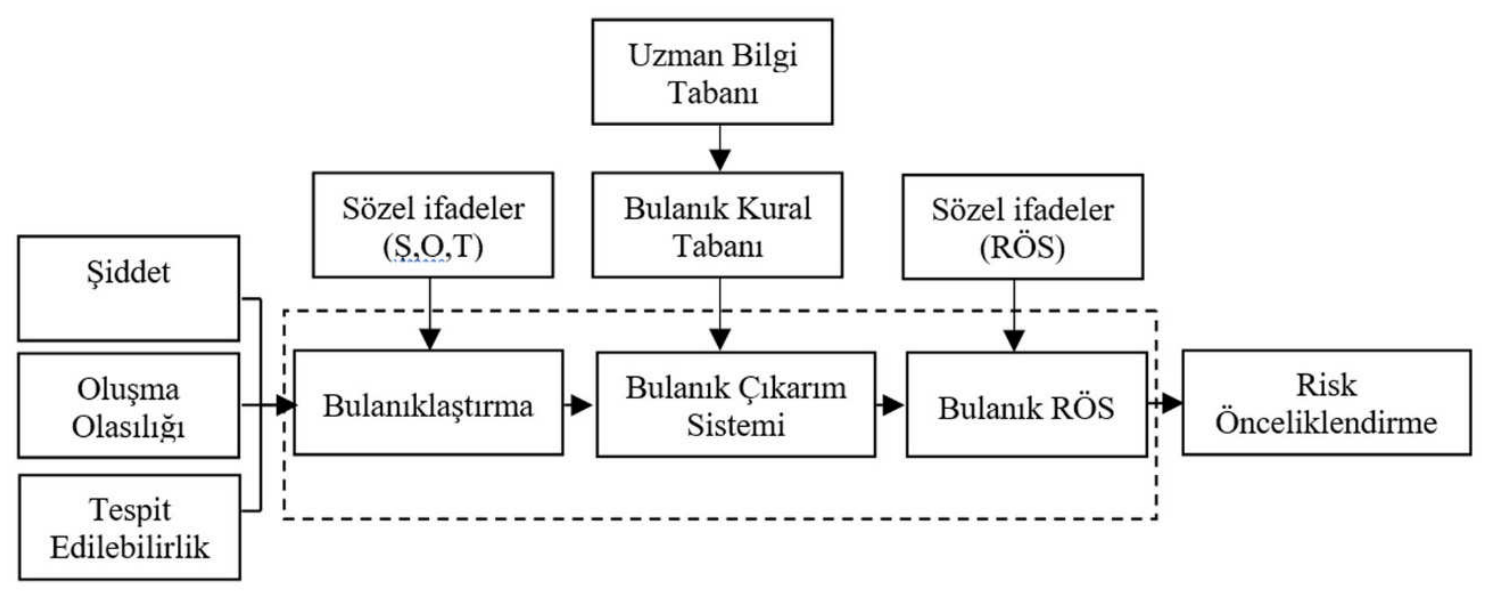

Şekil 2. Bulanık HTEA sisteminin adımları [30].

Şekil 2'de verilen Bulanık HTEA yönteminin uygulama sürecinde, HTEA yönteminde olduğu gibi incelenen sürece ilişkin hatalar, hataların nedenleri ve etkileri, mevcut kontroller, şiddet, oluşma ve tespit edilebilirlik değerleri belirlenmektedir. Şiddet, oluşma ve tespit edilebilirlik değerlerine ilişkin sözel terimlere karşılık gelen bulanık üyelik fonksiyonları, konusunda uzman ekip tarafından tanımlanmaktadır. Üyelik fonksiyonları yardımıyla gerçek veriler bulanıklaştırılarak bulanık şiddet, bulanık oluşma ve bulanık tespit edilebilirlik değerleri oluşturulmaktadır. HTEA için oluşturulan kural tabanındaki kurallar, hatanın oluşma olasılığı gibi nicel verilerin ve şiddet veya tespit edilebilirlik gibi niteliksel ve yargıya dayanan verilerin, tek bir cümle içinde kullanılmasına izin vermektedir. Kurallar, çıkarım motorunda işlenmekte ve hatanın riskine ilişkin bulanık sonuçlar elde edilmektedir. Durulama aşamasında, hata türleri değerlendirmekte, risk değerleri elde edilmekte ve elde edilen sonuçlara göre, düzeltici tedbirler alınmaktadır [30]. 


\section{Uygulama}

Çalışma Balıkesir ilinde transformatör üreten bir işletmede gerçekleştirilmiştir. İşletme iki farklı lokasyonda üretimini gerçekleştirmektedir. Ağır sanayi bölgesinde bulunan tesisinde güç ve dağıtım transformatörlerinin imalatlarını, organize sanayi bölgesinde bulunan ana tesisinde ise güç ve kuru tip transformatörlerin imalatlarını gerçekleştirmektedir. Çalışmada, işletme bünyesinde kullanılan malzeme maliyetlerinin ve işçilik giderlerinin büyük bölümünü oluşturan ve fïrmanın cirosu içinde en yüksek paya sahip olan güç transformatörlerinin (GT) üzerinde durulmuştur (Şekil 3). GT'nin üretim ve tasarım süreçlerinde yapılacak iyileştirmeler firmaya büyük maliyet avantajı ve itibar kazandıracağından, bu süreçlerde Bulanık HTEA uygulaması gerçekleştirilmiştir. Firma proje tipi imalat gerçekleştirmektedir. Bu da sipariş olarak alınan her ürünün tüm süreçlerinin baştan gerçekleştirilmesi anlamına gelmektedir. Tüm sürecin baştan değerlendirilmesi olası riskleri beraberinde getirmektedir. Gerçekleştirilen uygulamada klasik HTEA'nın eksik kaldığı RÖS hesaplama noktasında bulanık mantıktan yararlanılarak süreçte iyileştirme çalışmaları gerçekleştirilmiştir. HTEA kapsamında değerlendirilen tasarım ve üretim süreçleri için iki farklı ekip oluşturulmuştur. Tasarım HTEA ekibinde 7 çalışan, proses HTEA ekibinde 17 çalışan bulunmaktadır. Çalışmanın başlangıcında ilk olarak ekip üyelerinin süreçleri daha iyi değerlendirilmesi için süreçlere ait detaylı iş akış şemaları ekip lideri tarafından oluşturulmuştur. Akış şemaları ve HTEA formları şirket gizliliği açısından paylaşılamamaktadır.

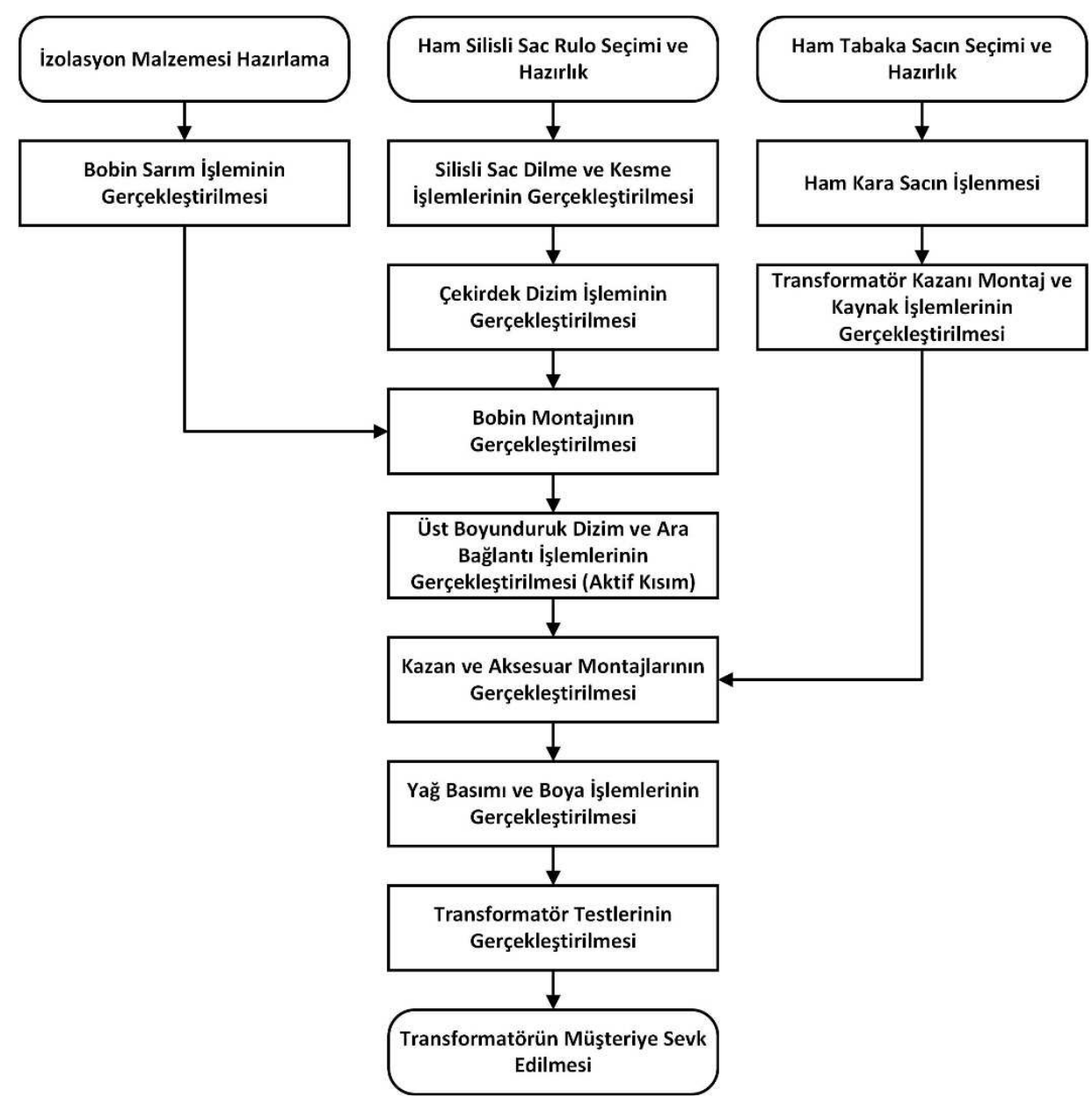

Şekil 3. Güç transformatörleri için üretim süreci. 
Tasarım süreci; teklif şartnamesinin incelenmesi ve maliyet ile birlikte teklifin oluşturulması, müşteriye gönderilecek dokümanların hazırlanması, siparişe dönüşen şartnamenin incelenmesi, elektrik tasarım süreçlerinin gerçekleştirilmesi (talimatının hazırlanması, bobin tasarımı, vb.) ve mekanik tasarım süreçleri (müșteri dokümanlarının hazırlanması, çekirdek-bağlantı-mekanik-son montaj gruplarının hazırlanması) aşamalarından oluşmaktadır. Üretim süreci Şekil 3'de görüldüğü gibi; çekirdek rulo dilimleme, çekirdek kesim, çekirdek dizim, bobinaj, kazan imalat, montaj, fırın, vakum alma ve yağ basma, son montaj ve sevkiyat, aşamalarından oluşmaktadır.

Akış şemaları ilgili tüm ekip üyelerine dağıtılmış ve birlikte incelenmiştir. $\mathrm{Bu}$ incelemede ekipte yer alan üyelerin bilgi, birikim ve tecrübelerinden faydalanılmıştır. Ayrıca geçmiş kalite verileri, müşteri şikayetleri ve ERP sisteminde yer alan süreçlere yönelik veriler değerlendirilmiştir. Sürecin doğru bir şekilde ilerlemesi amacıyla HTEA uygulama talimatı hazırlanmış ve bir kalite talimatı olarak firmada yayınlanmıştır. Bu kapsamda süreçlerde yer alan riskler, ekip üyeleri ile birlikte gerçekleştirilen düzenli toplantılarda belirlenmiştir. Her riske ait kök nedenler, risklerin oluşması durumunda etkileri, mevcut kontroller tespit edilmiştir. Daha sonra ekip üyeleri ile birlikte şiddet, olasılık ve tespit edilebilirlik değerleri için puanlama gerçekleştirilmiştir.

Çalışmada Bulanık HTEA yönteminden yararlanılmıştır. Klasik HTEA yöntemi ile elde edilen şiddet, olasılık ve tespit edilebilirlik değerleri bulanık sistemin oluşturulmasında girdi olarak kullanılmış, üyelik fonksiyonları, kural tabanı ve çıkış fonksiyonları oluşturulmuştur. Sürecin sonunda risklerin takibini sağlamak amaciyla Visual Studio programında C\# dilinde Bulanık HTEA'ya özel bir paket program yazılmıştır. Takip sistemi için veri tabanı olarak SQL Server Management Studio kullanılmıştır.

\subsection{HTEA uygulamasi}

Tasarım ve üretim süreçlerindeki riskler değerlendirilmiş ve tasarım süreci için toplam 129 adet risk, üretim süreci için toplam 217 adet risk tespit edilmiştir. Risklerin takibi için bir form hazırlanmış ve riskler bu forma işlenmiştir. Risk öncelik katsayıları ilk aşamada $R \ddot{O} S=$ Olasılı $\times \times$ Şiddet $\times$ Tespit Edilebilirlik formülünden hesaplanmıştır. Risklere ait RÖS'lerin değerlendirilmesi için pareto analizinden faydalanılmıştır. Pareto analizleri sonucunda tasarım HTEA için 81, proses HTEA için 132 risk \%20'lik dilime girmiştir. Bu risklere ek olarak şiddet değeri yüksek olup diğer iki faktörün düşük olması sebebi ile pareto analizinin \%20'lik diliminin dişında kalan tasarım HTEA için 9, proses HTEA için 5 tane risk bulunmaktadır. Riskler pareto analizi sonuçları ve şiddet değerlerinin yüksek olması dikkate alınarak değerlendirilmiş ve aksiyonlar belirlenmiştir. Yapılan değerlendirmeler sonucunda tasarım HTEA için 15, proses HTEA için 20 adet risk öncelikli aksiyon alınması gereken riskler olarak tespit edilmiştir (Tablo 1). Belirlenen riskler için alınması gereken önlemler ekip üyeleri ve ilgili personeller ile birlikte kararlaştırılmıştır. Belirlenen aksiyon planları; aksiyon planı bilgileri, sorumlu personel ve termin bilgileri ile birlikte HTEA formlarına işlenmiştir. Aksiyon planları sonucunda ağırlıklı olarak oluşma olasılığı ve tespit edilebilirlik değerlerinde \%40'a yakın iyileşmeler beklenmektedir.

\subsection{Bulanı HTEA uygulamasi}

Bulanık mantık yaklaşımıyla RÖS değerlerinin hesaplanması için MATLAB programında yer alan Fuzzy Logic Toolbox'dan yararlanılmıştır. HTEA tekniğinde RÖS hesabı için 3 girdi ve 1 çıktı değişkene sahip Şekil 4'deki model kurulmuş ve 3 faktör birleştirilerek RÖS hesaplanmıştır. 


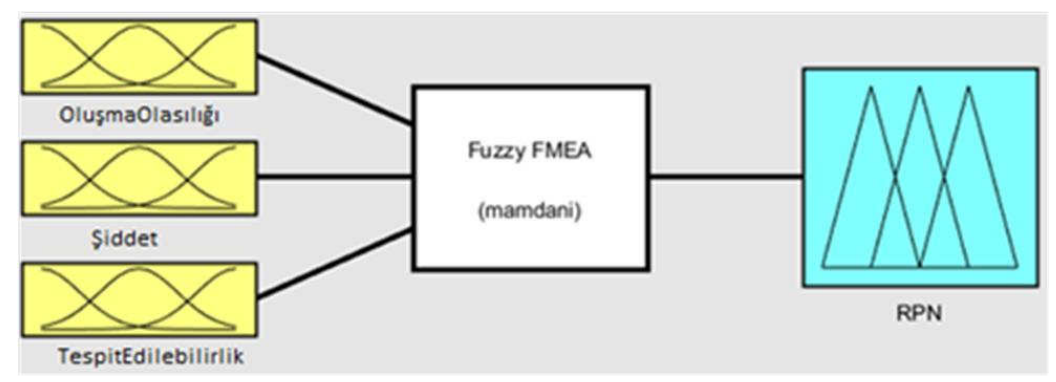

Şekil 4. Bulanık model.

Kurulan Bulanık HTEA modelinde şiddet, oluşma olasılığı ve tespit edilebilirlik girişleri için Şekil 5'deki üyelik fonksiyonu, RÖS çıktı değişkeni için ise Şekil 6'teki üyelik fonksiyonu kullanılmıştır.

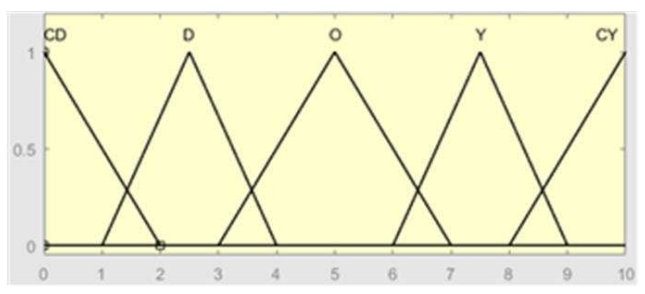

Şekil 5. Girdi değişkenleri üyelik fonksiyonu.

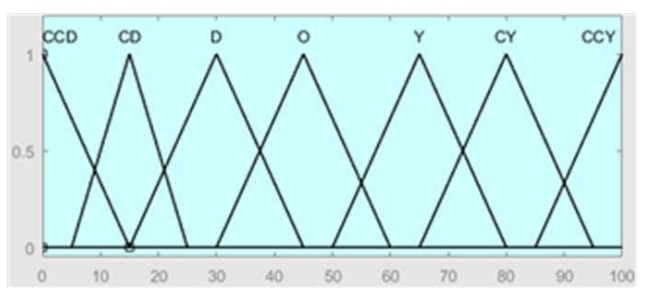

Şekil 6. Çıktı değişkeni üyelik fonksiyonu.

Şekil 5'de verilen grafikte girdiler için üyelik fonksiyonları oluşturulurken onlu skala kullanılmıştır. Üçgen üyelik fonksiyonları ile temsil edilen bu alt bölgeler; CD (çok düşük), D (düşük), O (orta), Y (yüksek) ve CY (çok yüksek) olmak üzere 5 farklı kümeye bölünmüştür. Çıktı değişkeni için ise Şekil 6'te yüz puanlık skala CCD (çok çok düşük), CD (çok düşük), D (düşük), O (orta), Y (yüksek), CY (çok yüksek) ve CCY (çok çok yüksek) olmak üzere 7 farklı kümeye bölünmüştür. Modelde 125 kuraldan oluşan bir kural tabanı oluşturulmuştur. Kurallar olası bütün durumlar tek tek değerlendirilerek tamamen uzman bilgisi dikkate alınarak hazırlanmıştır ve Şekil 7'da verilmiştir.

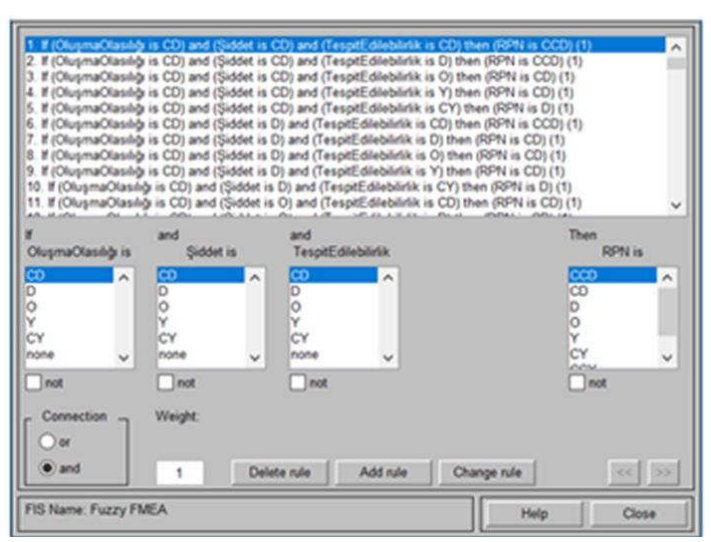

Şekil 7. Kural tabanı.

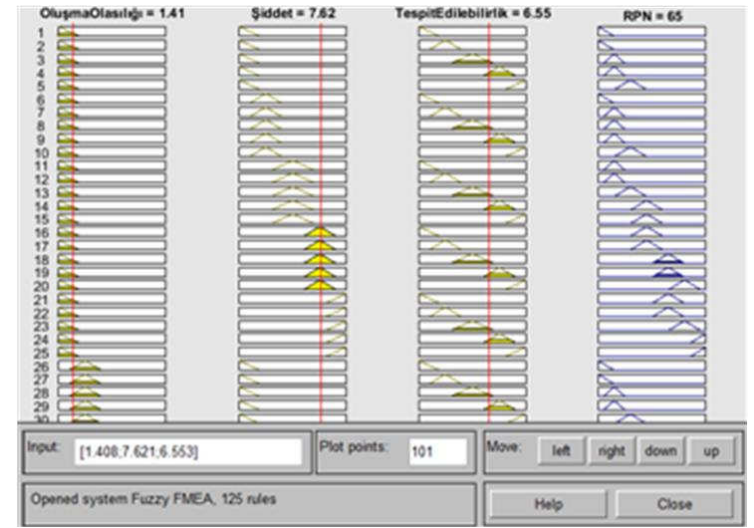

Şekil 8. Üç karar girdi değişkeni ile elde edilen çıktı değerinin bulanık kural tabanı görünümü (Matlab). 
Kural tabanının matlab görünümü Şekil 8'de verilmiştir. Çıkarım mekanizmasında mamdani yöntemi kullanılmış ve sonuçlar ağırlık merkezi yöntemi ile durulanmıştır. Kurulan bulanık model Matlab koduna dönüştürülmüştür. Bulanık HTEA yaklaşımı sonrası hesaplanan RÖS değerlerinin incelemesi pareto analizine göre yapılmıștır. Pareto analizleri sonucunda tasarım HTEA için 85, proses HTEA için 145 risk \%20'lik dilime girmiştir. Yapılan değerlendirmeler sonucunda tasarım HTEA için 15, proses HTEA için 20 adet risk öncelikli aksiyon alınması gereken riskler olarak klasik HTEA'nın aksine tek adımda tespit edilmiştir. Klasik ve Bulanık HTEA çalışmalarında belirlenen risklerin değerlendirme sonuçları Tablo 1'de özetlenmiştir.

Tablo 1. Klasik ve bulanık HTEA risk değerlendirme sonuçları.

\begin{tabular}{|l|c|c|c|c|}
\hline HTEA Türü & $\begin{array}{c}\text { Klasik Tasarım } \\
\text { HTEA }\end{array}$ & $\begin{array}{c}\text { Bulanık Tasarım } \\
\text { HTEA }\end{array}$ & $\begin{array}{c}\text { Klasik Süreç } \\
\text { HTEA }\end{array}$ & $\begin{array}{c}\text { Bulanık Süreç } \\
\text { HTEA }\end{array}$ \\
\hline Toplam risk (adet) & 129 & 129 & 217 & 217 \\
\hline $\begin{array}{l}\text { Pareto analizine göre \%20'lik } \\
\text { dilim içindeki riskler (adet) }\end{array}$ & 81 & 85 & 52 & 145 \\
\hline $\begin{array}{l}\text { Pareto analizine göre \%20'lik } \\
\text { dilimin dişında kalan şiddet } \\
\text { değeri yüksek riskler (adet) }\end{array}$ & 9 & - & 52 & - \\
\hline $\begin{array}{l}\text { Öncelikli aksiyon alınması } \\
\text { gereken riskler (adet) }\end{array}$ & 15 & 15 & 20 & 20 \\
\hline
\end{tabular}

Klasik HTEA ve Bulanık HTEA çalışmalarını karşılaştırmak amacıyla tasarım HTEA'dan alınan iki riskin değerleri Tablo 2' de verilmiştir. PT10A2 ve PT04A1 kodlu risklerin Klasik HTEA sonucuna göre aynı RÖS değerini aldıkları gözlenmiştir. Aynı RÖS değerleri elde edildiği için tasarım HTEA'nın risk öncelik sıralamasında eşit öneme sahip olduğu görülmektedir. RÖS değerlerine göre bu iki risk için önem derecesi aynıdır ve aynı dönemde aksiyon planı belirlenmesi gerekmektedir. Aynı risklerin Bulanık HTEA'ya göre belirlenen RÖS değerleri ve risk öncelik sıralamalarına bakıldığında iki riskin birbirleri ile aynı öneme sahip olmadıkları gözlenmiştir. Bu farkın nedeni Klasik HTEA'da risk faktörlerinin eşit önem derecesine sahip olması, Bulanık HTEA'da ise kural yapısı oluşturulurken şirketin yapısına uygun olarak risk faktörlerinden önem derecesinin ön planda tutulmasıdır.

Tablo 2. Klasik ve bulanık HTEA RÖS sıralamaları (Tasarım HTEA-Aynı RÖS örneği).

\begin{tabular}{|c|c|c|c|c|c|c|}
\hline HTEA & $\begin{array}{c}\text { Kök Neden } \\
\text { Kodu }\end{array}$ & Kök Neden & $\begin{array}{c}\text { Klasik } \\
\text { RÖS }\end{array}$ & $\begin{array}{c}\text { Klasik Yöntem } \\
\text { ile Öncelik } \\
\text { Siras1 }\end{array}$ & $\begin{array}{c}\text { Bulanık } \\
\text { RÖS }\end{array}$ & $\begin{array}{c}\text { Bulanık RÖS } \\
\text { ile Öncelik } \\
\text { Sıras }\end{array}$ \\
\hline Tasarım & PT10A2 & $\begin{array}{c}\text { Şartnamenin } \\
\text { içindeki } \\
\text { çelişkiler/Şartnameyi } \\
\text { kontrol edecek bir } \\
\text { yapının } \\
\text { bulunmaması }\end{array}$ & 120 & 20 & 65 & 41 \\
\hline Tasarım & PT04A1 & $\begin{array}{c}\text { Maliyet } \\
\text { dokümanlarına hatal } \\
\text { veri girişi }\end{array}$ & 120 & 21 & 45 & 64 \\
\hline
\end{tabular}

Yapılan HTEA çalışmalarında, yüksek olasılık ve tespit edilebilirlik derecelerine sahip bir risk düşük şiddet değerine sahip olduğunda; Klasik HTEA'nın önem sıralamasında üst sıralarda yer alıyorken, Bulanık HTEA'da daha alt sıralarda yer almaktadır. Şirket 
yapısı ve öncelikleri dikkate alındığında Bulanık HTEA'da risk faktörleri ağırlıklandırılırken şiddet faktörünün önem derecesi daha yüksek olduğu kabul edilmiștir. Bulanık HTEA ile yapılan değerlendirmenin risk faktörlerini ağırlıklandırdığı için daha doğru sonuç verdiği HTEA ekibi ile birlikte gözlenmiştir. Dolayısıyla Bulanık HTEA sistemi daha etkili bir çıkarımda bulunarak gerçeğe yakın bir sonuç vermiştir.

\subsection{Bulanık HTEA takip sistemi}

İşletmede Bulanık HTEA sisteminin sürekliliğini, takip kolaylığını, raporlanmasının hızlanmasını sağlamak amacıyla Bulanık HTEA risk takip programı yazılmıştır (Şekil 9). Takip sistemi Visual Studio programında C\# dilinde hazırlanmış ve veri tabanı olarak SQL Server Management Studio kullanılmıştır. Takip sistemi içerisinde Bulanık RÖS hesabını yapabilmek için Matlab programında kurulan modelden yararlanılmıştır.

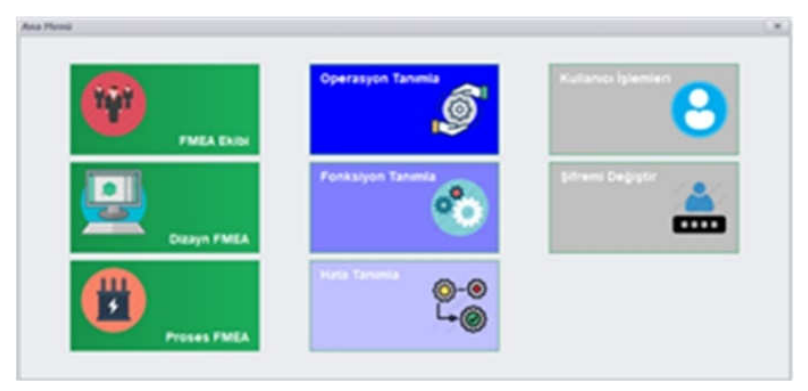

Şekil 9. Bulanık HTEA risk takip programı ana ekran görüntüsü.

Hazırlanan takip sisteminde, Tasarım ve Proses HTEA çalışmalarında görev alacak ekip üyelerine ait bilgilerin girilebileceği HTEA Ekibi butonu, Bulanık HTEA çalışmalarında belirlenen risklere ve risklere ait bilgilere (etkisi, mevcut kontrol, RÖS, Eski Dönem RÖS ...) ulaşabileceğimiz Tasarım HTEA ve Proses HTEA butonları yer almaktadır. Buradan RÖS hesabı ve RÖS değerlerine göre pareto analizi ile riskler önceliklendirilebilmekte, ayrıca risklere ait aksiyonlar girilebilmekte ve mevcut aksiyonların takibi gerçekleştirilmektedir. Operasyon Tanımla butonundan yeni operasyon kaydı veya mevcut operasyon işlemleri yapılabilmektedir. Fonksiyon ve hata tanımlama butonları ile de operasyon tanımlama işlemlerine benzer şekilde işlemler gerçekleştirilmekte ve tüm işlemler excel formuna aktarılabilmektedir. Program ile HTEA çalışmaları bir database üzerinde takip edilebilecektir. Bu da kişi bazlı yapılacak hatalı veri girişlerini en aza indirmiş ve doküman kalabalığından oluşabilecek kargaşaların önüne geçilmesini sağlamıştır. Program üzerinde RÖS değerlerinin bulanık mantık ile tespit edilmesi, riskler üzerinde daha doğru bir önceliklendirme yapılmasını sağlamıştır.

\section{Sonuçlar}

Günümüzde yaşanan rekabet koşullarında, risklerin oluşmadan önlenerek güvenilirliğin artırılması kaçınılmaz noktaya gelmiştir. Geçmişten günümüze; ürün ve proses güvenilirliğinin artırılması için birçok yöntem ortaya atılmıştır. HTEA bu tekniklerden biri olup oldukça yaygın bir uygulama alanına sahiptir. Klasik HTEA hata türlerini sıralamak için risk öncelik sayısını kullanmaktadır. Ancak son zamanlarda risk öncelik sayısının hesaplanması noktasında bazı eksikler olduğu görülmektedir. Klasik HTEA'nın eksik kaldığı RÖS hesabı için birçok değişiklik yapılmış ve farklı yöntemler 
uygulanmaya çalışılmıştır. Bu yöntemlerin en başında bulanık mantık gelmektedir. Bulanık mantık bu aşamada dilsel değişkenleri değerlere dönüştürmek için klasik bir yöntemdir.

$\mathrm{Bu}$ çalışma kapsamında bir transformatör üreten işletmenin güç transformatörlerinin tasarım ve proses süreçlerinde Bulanık HTEA çalışması gerçekleştirilmiştir ve firma bünyesine bir talimat ile kalite standardı olarak entegre edilmiştir.

Çalışmada, klasik HTEA mantığı ile yapılan değerlendirmede; tasarım HTEA için 81, proses HTEA için 132 risk kritik bölgede bulunmuştur. Bulanık HTEA ile yapılan değerlendirmede ise; tasarım HTEA için 85, proses HTEA için 145 risk kritik bölgede bulunmuştur. $\mathrm{Bu}$ da Bulanık HTEA yönteminin daha fazla risk grup aralığı oluşturduğunu ve daha hassas bir değerlendirme yaptığını göstermektedir. Klasik HTEA'ya göre yüksek olan RÖS değeri Bulanık HTEA'da daha düşük, düşük olan değerler ise daha yüksek çıkmıştır. Bu farkın oluşmasının nedeni Bulanık HTEA'da kural yapısı oluşturulurken risklerin önem derecelerinin dikkate alınmasıdır. Şirket yapısı ve öncelikleri dikkate alındığında Bulanık HTEA'da risk faktörleri ağırlıklandırılırken şiddet faktörünün önem derecesinin daha yüksek olduğu kabul edilmiştir. Bulanık HTEA ile yapılan değerlendirmenin risk faktörlerini ağırlıklandırdığı için daha doğru sonuç verdiği HTEA ekibi ile birlikte gözlenmiştir.

Klasik HTEA ve Bulanık HTEA analizlerine istinaden ekip üyeleri ile yapılan görüşmeler sonucunda tasarım HTEA için 15, proses HTEA için 20 adet riske öncelikli olarak sorumlu ve termin bilgileri ile birlikte aksiyon belirlenmiştir. Aksiyon planları sonucunda ağırlıklı olarak oluşma olasılığı ve tespit edilebilirlik değerlerinde \%40'a yakın iyileşmeler öngörülmektedir. Çalışmada HTEA süreçlerinin etkin takibi için kullanıcı dostu ara yüze sahip bir takip sistemi geliştirilmiştir. RÖS hesabı Bulanık HTEA Risk Takip sistemi içerisinde Matlab'da kurulan denklem sayesinde gerçekleştirilmektedir. Elde edilen sonuçlar, işletme tarafından anlamlı bulunmuştur. İşletme, kurulan yapı sayesinde üretim ve tasarım esnasında karşılaşılabilecek olası risklere hazırlıklı olabilecektir. Dolayısıyla işyerinde olası risklerden kaynaklanan zaman, maliyet ve iş gücünden kazanım sağlayacağı öngörülmektedir.

\section{Teşekkür}

Çalışmaya katkılarından dolayı Balıkesir Elektromekanik Sanayi Tesisleri A.Ş.'ye teşekkür ederiz.

\section{Kaynaklar}

[1] Efe, B., Yerlikaya, M.A. ve Efe, Ö.F., İş güvenliğinde bulanık promethee yöntemiyle hata türleri ve etkilerinin analizi: bir inşaat firmasında uygulama, Gazi Üniversitesi Mühendislik-Mimarlık Fakültesi Dergisi, 6(2), 126-137, (2016).

[2] Musubeyli Erginel, N., Tasarım hata türü ve etkileri analizinin etkinliği için bir model uygulaması, Makine Mühendisleri Odası Endüstri Mühendisliği Dergisi, 15(3), 17-26, (2004). 
[3] Aran, G. ve Çevik, O., Kalite iyileştirme sürecinde hata türü etkileri analizi (fmea) ve piston üretiminde bir uygulama, SÜ İiBF Sosyal ve Ekonomik Araştırmalar Dergisi, 16, 241-265, (2009).

[4] Dirağ, A., Failure Mode and Effects Analysis (FMEA) and an implementation study in a packaging company. Yüksek Lisans, Fen Bilimleri Enstitüsü, Endüstri Mühendisliği Anabilim Dalı, İstanbul, (2008).

[5] Demirer, A. ve Kahraman, Ö., OHSAS 18001 Kapsamında FMEA uygulamas1, Makine Teknolojileri Elektronik Dergisi, 7(1), 53-68, (2010).

[6] Çeber, Y., Hata türü ve etkileri analizi yönteminin (fmea) üretim sektöründe uygulanmas1, Yüksek Lisans, Sosyal Bilimler Enstitüsü, Toplam Kalite Yönetimi Anabilim Dalı, İzmir, (2010).

[7] Şimşir F., Demir H.İ., Azdemir S., Demir çelik sektöründe hibrid DEMATEL ve TOPSIS-ELECTRE yöntemleri ile hata türleri ve etkileri analizi, Academic Platform Journal of Engineering and Science, 6-3, 22-34, (2018).

[8] Elmas, Ç., Bulanık Mantık Denetleyiciler (Kuram, Uygulama, Sinirsel Bulanık Mantık), Ankara: Seçkin Yayıncılık San. ve Tic. A.Ş., 24-125, (2003).

[9] Baynal, K. ve Terzi, Ü., Taguchi yöntemi ve bulanık mantık kullanılarak üretim parametrelerinin eşzamanlı eniyilenmesi, Yöneylem Araştırması/Endüstri Mühendisliği - XXIV Ulusal Kongresi, Gaziantep-Adana, (2004).

[10] Bayar, N., İstanbul Boğaz'ında deniz trafik güvenliğinin risk tabanlı bulanıkAHP ve FMEA yöntemleri ile incelenmesi. Doktora Tezi, Yıldız Teknik Üniversitesi, Fen Bilimleri Enstitüsü, İstanbul, (2010).

[11] Dinmohammadi, F. ve Shafiee, M., A fuzzy-FMEA risk assessment approach for offshore wind turbines, International Journal of Prognostics and Health Management, 13, ISSN 2153-2648, 1-10, (2013).

[12] Yörükoğlu, H., Yenilenebilir enerji kaynakları risklerinin bulanık-fmea yöntemi ile analizi, Yüksek Lisans Tezi, Kocaeli Üniversitesi, Fen Bilimleri Enstitüsü, Kocaeli, (2014).

[13] Özfırat, P.M., Bulanık önceliklendirme metodu ve hata türü ve etkileri analizini birleştiren yeni bir risk analizi yöntemi, Journal of the Faculty of Engineering and Architecture of Gazi University, 29(4), 755-768, (2014).

[14] Çakmak, M., Demir-çelik sektöründe bulanık hata türleri ve etkileri analiz (bulanık fmea) yöntemi ile risk değerlendirme uygulaması, Yüksek Lisans Tezi, Karabük Üniversitesi, Fen Bilimleri Enstitüsü, Karabük, (2015).

[15] Roghanian, E. ve Mojibian, F., Using fuzzy FMEA and fuzzy logic in project risk management, Iranian Journal of Management Studies (IJMS), 8(3), 373395, (2015).

[16] Hayati, M. ve Abroshan, M. R., Risk Assessment using Fuzzy FMEA (Case Study: Tehran Subway Tunneling Operations), Indian Journal of Science and Technology, 10(9), 1-9, (2017).

[17] M. Yazdi, S. Daneshvar, H. Setareh, An extension to fuzzy developed failure mode and effects analysis (FDFMEA) application for aircraft landing system, Safety Science, 98, 113-123, (2017).

[18] Tekez E.K, Failure modes and effects analysis using fuzzy topsis in knitting process, Tekstil ve Konfeksiyon, 28(1), (2018).

[19] Toptancı, Ş. ve Erginel, N., Hata türü ve etkileri analizi ve kalite fonksiyon yayılımı ile bir inşaat firması için risk değerlendirmesi, Mühendislik Bilimleri ve Tasarım Dergisi, 5 (ÖS: Ergonomi2016), 189-199, (2017). 
[20] Deng, X. ve Jiang, W., Fuzzy risk evaluation in failure mode and effects analysis using a d numbers based multi-sensor information fusion method, School of Electronics and Information, 17, 2086, 1-17, (2017).

[21] Kahraman, Ö., Bir otomobil fabrikasında iș sağlığı ve güvenliği alanında HTEA (FMEA) yöntemi ile risk analizi, Yüksek Lisans, Sakarya Üniversitesi, Fen Bilimleri Enstitüsü,Sakarya, (2009).

[22] Efe, B., Kurt, M. ve Efe, Ö.F., An integrated intuitionistic fuzzy set and mathematical programming approach or an occupational health and safety polic, Journal of the Faculty of Engineering and Architecture of Gazi University, 30(2), 73-95, (2017).

[23] Dağsuyu, C., Göçmen, E., Narlı, M. ve Kokangül, A., Classical and fuzzy FMEA risk analysis in a sterilization unit, Cukurova University Computers \&Industrial Engineering, 101, 2016, 286-294, (2016).

[24] Gönen, D., Hata türleri ve etkileri analizi ve bir uygulama çalışması, Yayınlanmış Yüksek Lisans Tezi, Balıkesir Üniversitesi, Balıkesir, (2004).

[25] Shirouyehzad, H., Badakhshian, M., Dabestani, R. ve Panjehfouladgaran, H., Fuzzy FMEA analysis for identification and control of failure preferences in ERP implementation, The Journal of Mathematics and Computer Science, 1(4), 366-376, (2010).

[26] Aytaç, E., Kalite iyileştirme sürecinde bulanık mantık yaklaşımı ile hata türü ve etkileri analizi ve uygulama örneği, Doktora Tezi, Adnan Menderes Üniversitesi, Sosyal Bilimler Enstitüsü,Aydın, (2011).

[27] Eskioğlu, H., Ürün geliştirmede bulanık kalite fonksiyonu göçerimi endüstriyel bir uygulama, Yüksek Lisans Tezi, Kocaeli Üniversitesi, Fen Bilimleri Enstitüsü, Kocaeli, (2012).

[28] Bodur, K., Bulanık mantık yaklaşımı ile deprem konumlarının belirlenmesi, Yüksek Lisans, Fen Bilimleri Enstitüsü, Jeofizik Mühendisliği Anabilim Dalı, Trabzon, (2012).

[29] Chanamool, N. ve Naenna, T., Bulanık FMEA application to improve decisionmaking process in an emergency department, Applied Soft Computing, 43, 2016, 441-453, (2016).

[30] Khasha R., Sepehri M.M., Khatibi T., Fuzzy FMEA approach to prioritizing surgical cancellation factors, International Journal of Hospital Research, 2(1), 17-24, (2013). 